\title{
Kinetic and Isothermal Investigations of Cost-Effective Sorptive Elimination of Gentian Violet Dye from Water Using Haplophragma adenophyllum Biowaste
}

\author{
Momal Akram, ${ }^{1}$ Muhammad Salman, ${ }^{1}$ Rabia $\operatorname{Rehman~} \mathbb{D}^{1},{ }^{1}$ Umar Farooq, ${ }^{1}$ Samra Tahir, \\ and Huma Nazir ${ }^{1,2}$ \\ ${ }^{1}$ School of Chemistry, University of the Punjab, Quaid-e-Azam Campus, Lahore 54590, Pakistan \\ ${ }^{2}$ University of Education, Bank Road Campus, Lahore, Pakistan \\ Correspondence should be addressed to Rabia Rehman; grinorganic@yahoo.com
}

Received 13 February 2021; Revised 24 March 2021; Accepted 21 April 2021; Published 28 April 2021

Academic Editor: Gulaim A. Seisenbaeva

Copyright (C) 2021 Momal Akram et al. This is an open access article distributed under the Creative Commons Attribution License, which permits unrestricted use, distribution, and reproduction in any medium, provided the original work is properly cited.

\begin{abstract}
A novel biosorbent, Haplophragma adenophyllum (HAB) was employed to explore the biosorption mechanism of Gentian Violet (GV) dye. The novel sorbent was characterized by using FTIR spectra and physiochemical analysis. The effect of different optimizing factors like $\mathrm{HAB}$ dosage, GV initial concentration, contact time between sorbent and sorbate, $\mathrm{pH}$ of a solution, and the temperature was studied. The optimum removal of GV by HAB was observed at $\mathrm{pH}$ 6.0. The equilibrium study was carried out using Langmuir and Freundlich isotherms. Experimental data fitted well in Langmuir isotherm indicating monolayer isotherm with $q_{\max }$ value obtained at optimum process condition of $13.21 \mathrm{mg} / \mathrm{g}$. Kinetics study was carried out and followed by pseudosecond-order model. Thermodynamics studies reveal the endothermic reaction.
\end{abstract}

\section{Introduction}

The fortification of various ecosystems is an enormous challenge for researchers in these times of intense population increase era and technological development, especially in third-world countries. The significance of the treatment for the poisonous toxins has gradually become clear owing to the profound nuisance of human-induced environmental contamination in several systems [1]. Water as the most precious resource for human beings' survival is tackling exceptional fears. Water pollution has been turned into several of the world's most genuine concerns. A freshwater environment is a fundamental need for both people and wildlife. Even so, this scenario is yet dissemination; plenty of wastewater has been created and released towards the natural freshwater bodies.

Among various types of wastewater, dye polluted wastewater deserves being taken into consideration. Dyes are nonrecyclable chemicals that will continue to remain stationary under different circumstances, having either direct or indirect poisonous impact on people because they are associated with cancer, yellow fever, tumours, irritation to the skin, allergies, cardiac defects, and mutations [2-5]. Amidst all the emissions resulting from the industry, one of the commonly used organic dyes is Gentian Violet (GV) or Crystal Violet, a triphenylmethane dyestuff, utilized in garments and textiles for dyeing the stuff. It is also used in paper print and in the veterinary as well as biological staining $[6,7]$. GV is universally used throughout the healthcare society, amazingly well known to trigger several health problems. Taking this into account, GV dye had been reported to be causing mild eye discomfort and sore sensitizing towards the light along with permanent damage to the corneal and connective tissue of the eyes. It is highly toxic to the mammals' cells, causing skin irritations and gastrointestinal tract inflammation [8]. It could also lead to breathing difficulties and renal failure under extreme circumstances [9-11]. Their elimination from waste discharges is hard, owing to their high level of organic structural intricacy. The extermination of GV dyestuff from the aquatic 
bodies is extraordinarily essential for the improvement of water quality for citizens.

Numerous methods are currently being adopted such as adsorption [12], biodegradation [13, 14], flocculation [15, 16], oxidation process $[17,18]$, ion exchange $[19,20]$, nanofiltration/ultrafiltration [21-24], electrocoagulation $[25,26]$, electrodialysis $[27,28]$, electroflotation $[29,30]$, ozonation [31, 32], photochemical oxidation [33], reverse osmosis [34, 35], etc., intended for the treatment of GV wastewater. While using these costly physical and chemical techniques, a massive amount of muck is generated; this leads to the second point of terrestrial contamination of our ecosystem. It must be noted that the traditional approaches are also subject to altercations in the manufacturing of focused streams, involve excessive power consumption, and are very costly [1]. For the very same, there is a pressing need to discover an affordable, ecofriendly method used for the elimination of the organic pollutant dyes.

Adsorption is considered to be one of the most frequently used methods for eliminating a broad range of active ingredients. This method has been taken into account as one of the most effective and efficient and inexpensive methods owing to its benefits comprising the subsequent: This is a simple operation with easy handling and is cost-effective, ecological, and available for various adsorbent materials. [1, 36-38]. Several types of adsorbents, counting natural wastes, natural zeolite, polymers, fly ash, chitosan, lemongrass leaf, modified activated carbon, metal nanoparticles, magnetic chitosan nanocomposite, sugarcane bagasse, cornstalk, water hyacinth, and carbon-based nanomaterials, have been employed [39-45]. Exclusion of a variety of toxins by biosorption on lignocellulosic raw material has also been confirmed as having been an encouraging and expenditureefficient technique. Massive heaps of lignocellulosic materials are being generated every single day, such as waste generated from the food products and lumber industry sectors, and a whole lot of it ends up around landfill sites. Such wastes are inexpensive and frequently available throughout the year; hence their implementation as biosorbents has several advantages, which are a lessening of waste disposal and the elimination of contaminants from the environment [46].

The main objective of this investigation was to discover the new biowaste, i.e., Haplophragma adenophyllum, as well as identifying its binding sites that can be used for the elimination of the dye in terms of binding capacity. This plant belongs to the family Bignoniaceae of plants and is commonly referred to as "Naag Phali" in zones of Pakistan, utilized in conventional medicine as a component in oils intended to lessen muscle tension.

\section{Experimental Work}

2.1. Collection of Haplophragma adenophyllum Biomass $(H A B)$. Being an agricultural waste, $\mathrm{HAB}$ has been gathered at a local level from the botanical gardens of the University of the Punjab, washed, and air-dried. Dried-up HAB was beached and sieved through the mesh assortment of 70ASTM. This particular grain-sized biomass turned out to be cleaned over and over again by using distilled water up until there is no pigmentation as well as dust particulate matter left. It was dried at $70^{\circ} \mathrm{C}$ in oven and then stored in plastic jars till further use.

2.2. Simulated GV Solutions. The acquired GV dye (molecular formula $\mathrm{C}_{25} \mathrm{~N}_{3} \mathrm{H}_{30} \mathrm{Cl}$; $\lambda \max =590 \mathrm{~nm}$ ) used in the trials was pure and is used with no additional cleansing. The stock solution of $\mathrm{GV}$ dye $\left(1000 \mathrm{mgL}^{-1}\right)$ was made by weighing the precise measurements of the dye in the purified water. The working solutions intended for further investigation had been prepared from the stock solution through getting an accurate volume from it.

2.3. Spectroscopic and Physiochemical Analysis of $H A B$. FTIR and SEM analysis have been used to illustrate the major functional groups accountable for binding upon the surface of HAB and the surface texture. Moreover, Boehm's titration was intended for the concentration of acidic and basic groups on the surface of HAB.

There are many techniques, i.e., mass titration, immersion method, potentiometric titration, and $\mathrm{pH}$ drift method, to measure pHpzc [47]. From all the abovementioned methods, the $\mathrm{pH}$ drift method was utilized as a reliable method. According to this method [48], $\mathrm{pH}$ of electrolyte, i.e., $\mathrm{KCl}$, was set down by using $\mathrm{KOH}$ and $\mathrm{HNO}_{3}$ in the range of 2-10 and after adding $0.1 \mathrm{~g}$ of $\mathrm{HAB}$, it was agitated for 24 hours. Final pH was measured after 48 hours and a plot was drawn between initial and final $\mathrm{pH}$ and the point was chosen where initial and final $\mathrm{pH}$ become equal at the cutoff point.

2.4. Batch Studies. The procedure had been carried out in the batch mode at orbital shaking platform at $150 \mathrm{rpm}$ to discover the ideal parameters designed for the adsorption of GV like $\mathrm{HAB}$ quantity $(0.1-0.9 \mathrm{~g})$, a contact time of sorption (5-180 min), temperature (283.16-333.16 K), and pH (2-10). To achieve the best possible conditions a significant amount of $\mathrm{HAB}(100 \mathrm{mg})$ has been added to the GV solution of known strength $(50 \mathrm{mg} / \mathrm{L}, 50 \mathrm{~mL})$. After a certain period, the blend was filtered, and remains have been analyzed utilizing UV/VISIBLE Research Spectrophotometer (LABOMED, 3500) at a particular wavelength. Each parameter is evaluated in each step by maintaining persistent additional factors within the further process. Then optimized conditions were used for kinetic, isothermal, and thermodynamic investigations to compute adsorption equilibrium time and mechanism of GV dye removal by $\mathrm{HAB}$ with maximum sorption capacity. The amount of adsorption $\left(q_{e}\right)$ was determined by using the following equations:

$$
q_{e}=\frac{\left(C_{i}-C_{e}\right) V}{m}
$$

The percentage removal $(R \%)$ of dyes can be calculated as

$$
R \%=\frac{\left(C_{i}-C_{e}\right)}{C_{i}} \times 100 .
$$




\section{Result and Discussion}

3.1. Characterization of $H A B$. Raw $\mathrm{HAB}$ and GV loaded HAB were subject to FTIR analysis (Agilent Technologies CARY 630 FTIR) to observe the possible binding sites present on $\mathrm{HAB}$ and incorporation of GV onto the surface of HAB. The FTIR spectrum is shown in Figure 1.

This shows the occurrence of a variety of functional groups that could be the prospective binding locations for dye molecules. The peak observed at $3301.17 \mathrm{~cm}^{-1}$ in raw $\mathrm{HAB}$ indicated the presence of $-\mathrm{OH}$ groups and the peak area observed between $1597.84 \mathrm{~cm}^{-1}$ and $1702.44 \mathrm{~cm}^{-1}$ indicated the presence of $\mathrm{C}=\mathrm{O}$ groups as potential binding sites for surface attachment of GV. The statement was reinforced by noticing the GV loaded FTIR spectrum in which significant shifts and change in peak intensities in these functional groups' area were observed. Also, the sharp peaks that appeared at $2368.44 \mathrm{~cm}^{-1}$ and $2323.25 \mathrm{~cm}^{-1}$ indicate the presence of nitrogen linkage, which is present in the structure of GV affirming the incorporation of GV onto the surface structure of $\mathrm{HAB}$.

Whenever equilibrium is established between negatively charged and positively charged active sites on the surface at a specific $\mathrm{pH}$, that point is referred to as a point of zero charge $\left(\mathrm{pH}_{\mathrm{pzc}}\right)$. At this point, the surface charge is neutral or zero. Whenever a variation happens in $\mathrm{pH}$ from the angle of $\mathrm{pH}_{\mathrm{pzc}}$ an equilibrium is upset [49]. This information helps to theorize the ionization of responsible functional groups and then their interaction with dye molecules present in a solution. When solution $\mathrm{pH}$ goes higher than $\mathrm{pHpzc}$, the surface will be negatively charged and interact with positive species while going lower from this point, the surface will be positively charged interacting with negative species. This description is extremely important for the fortitude of the best possible terms and conditions to be carried out on a massive scale.

The value of pHpzc is tabulated in Table 1 and the cutoff graph obtained as a result of the pHpzc drift method in Figure 2 shows the $\mathrm{pHpzc}$ value, i.e., $\mathrm{pH} 6.0$ where initial and final $\mathrm{pH}$ become equal showing the neutral point.

For the determination of acidic and basic functional group concentration, the most utilized method, i.e., Boehm's titration, was utilized. Raw $\mathrm{HAB}$ has interacted with acid, i.e., $\mathrm{HCl}$, and bases, i.e., $\mathrm{NaOH}, \mathrm{Na}_{2} \mathrm{CO}_{3}$, and $\mathrm{NaHCO}_{3}$. Their concentrations were calculated by titration and tabulated in Table 1 . It is also showing other physiochemical parameters, which were determined by standard methods. It indicated that no harmful element is present in $\mathrm{HAB}$ which can pose harm to environment. Moisture contents and iodine number also prove its suitability as biosorbent. Less moisture indicates that its biodegradability will be slow, which will increase its shelf-life. More iodine number indicated its unsaturated nature, which is parrel to FTIR results.

\subsection{The Factors Influencing Removal of $G V$}

3.2.1. Influence of $H A B$ Dosage on GV Removal. The adsorption of GV has been observed in the batch scheme. Taking this into account sorption procedure was analyzed at an initial concentration of $50 \mathrm{mg} / \mathrm{L}$. An increase in the quantity of $\mathrm{HAB}(0.1-0.9 \mathrm{~g})$ was used and results are shown in Figure 3.

As observed in Figure 3, it is pointed out that increasing the amount of the HAB percentage of removal $(\% R)$ also increased at the same moment. This sort of trend occurring could be due to the approachable openings that occur on the frontage of the surface. An increase in the percentage can be attributed to the higher amount sites available on sorbent for the binding of dye as well as the increased surface area of sorbent by increasing dosage amount [50] and also, on the other hand, the rise of $\% \mathrm{R}$ by an increasing amount of sorbent leads to a reduction in the adsorption capacity $\left(q_{e}\right)$, which reveals the inverse relationship at this point. This sort of trend might exist because of the pores unavailability on the frontage of the surface or else due to the accumulation of active sites [51]. On a dosage exceeding $0.3 \mathrm{~g} / \mathrm{L}, \% R$ has not made a significant alteration due to aggregation of $\mathrm{GV}$ molecules on the surface of sorbent, which might reduce the number of available binding sites. A substantial reduction in $q_{e}$ value has been observed depending on an increase in the sorbent mass, which might be due to reduction in the unit mass of dye removed by sorption onto the surface of biowaste. Therefore, increasing the mass to a particular level decreases the amount of GV bound onto unit mass of HAB $[50,52]$. Next, the maximum possible $\% R$ of $G V$ recorded was $88.50 \%$ at $0.9 \mathrm{~g} / \mathrm{L}$. Nevertheless, there has been no encouraging outcome attained by increasing the amount of $\mathrm{HAB}$. In short, $0.9 \mathrm{~g} / \mathrm{L}$ of sorbent was regarded as an optimized weight.

\subsubsection{Influence of $p H$ Potency on the Removal of $G V$} The $\mathrm{pH}$ plays a significant part in the removal of dye molecules especially in the sorption process as compared to metal ions. When alteration occurs in the $\mathrm{pH}$ of sorbate it also impacts the surface charge of dye molecules. This trend may be due to the degree of ionization of dye [53]. For the sake of color and structural stability, $\mathrm{pH}$ potency plays an important part.

The contest among $\mathrm{H}^{+}$and dye molecules on the active surface of the sorbent is controlled by $\mathrm{pH}$. In the recent study, the $\mathrm{pH}$ potency was varied between 2 and 10, and the trend is explained in Figure 4. From the obtained experimental data, higher removal percentage was observed at $\mathrm{pH}$ 6.0. From this point forward increase in $\mathrm{pH}$ potency does not favor the removal of dyes. As GV is basic, it is present as positively charged in solution. At low $\mathrm{pH}$ potency, the positively charged surface repels the positively charged GV molecule which in result shows low sorption in an acidic medium. On the other hand, in the basic medium, the trend becomes reversed resulting in the sorption of $\mathrm{GV}$ molecules.

In the solution, $\mathrm{GV}$ exists in two forms, i.e., $\mathrm{GV}^{+}$(cationic) and GV leucocarbinol (anionic). Both forms are interconvertible and equilibrium between them depends upon $\mathrm{pH}$ potency (Figure 5) $[54,55]$. The $\mathrm{pH}_{\mathrm{pzc}}$ of HAB was determined by $\mathrm{pH}$ drift method giving cutoff point of 6.0 (Figure 3). At $\mathrm{pH}$ lower than this point, it is present as $\mathrm{GV}^{+}$ indicating the positive charge on surface of $\mathrm{HAB}$ and vice 


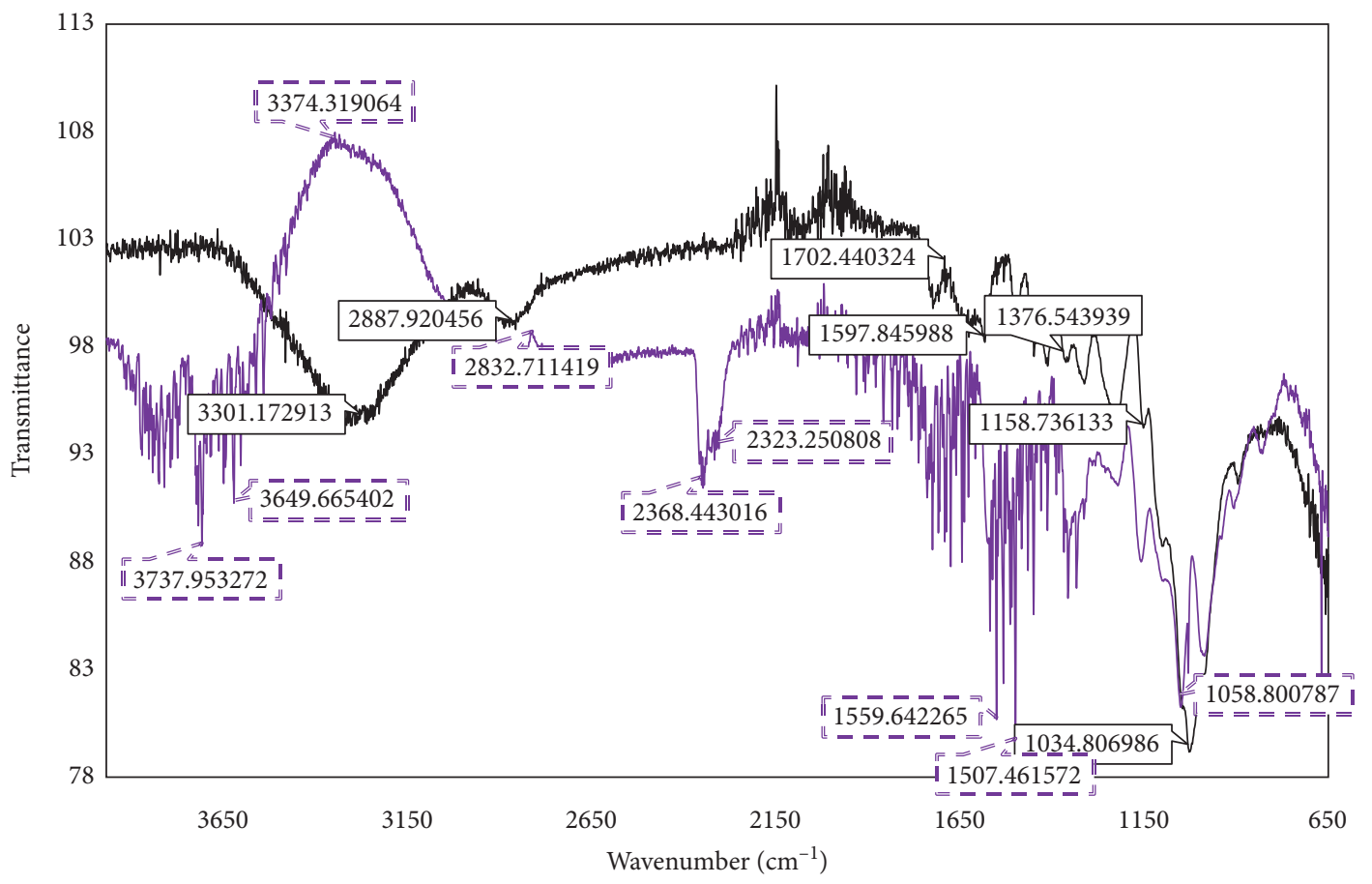

Raw HAB

CV Loaded HAB

FIgUre 1: FTIR spectra of raw HAB and GV loaded HAB.

TABle 1: Physiochemical characterization of Heterophragma adenophyllum.

\begin{tabular}{lc}
\hline Characterization & Results \\
\hline Moisture content\% & 9 \\
Iodine number $(\mathrm{mg} / \mathrm{g})$ & 24.18 \\
$\mathrm{pH}_{\mathrm{pzc}}$ & $6.0 \pm 0.01$ \\
& Total acidic $=32.5 \pm 0.02$ \\
& COOH groups $=5.89 \pm 0.02$ \\
Acidic and basic species & Lactones $=18.5 \pm 0.02$ \\
$(\mathrm{mmol} / \mathrm{g})$ & Phenols $=7.75 \pm 0.02$ \\
& Basic nature \\
& moieties $=24.75 \pm 0.02$ \\
\hline Elemental analysis $(\mu \mathrm{mol} / g)$ & \\
$\mathrm{Cd}^{2+}$ & 1.2191 \\
$\mathrm{Ni}^{2+}$ & 0 \\
$\mathrm{Zn}^{2+}$ & 0 \\
$\mathrm{~Pb}^{2+}$ & 0.5029 \\
$\mathrm{Mg}^{2+}$ & 1.704 \\
$\mathrm{Ca}^{2+}$ & 0.045 \\
$\mathrm{~K}^{+}$ & 0.11 \\
$\mathrm{Na}^{+}$ & 0.54 \\
\hline
\end{tabular}

versa. In between the $\mathrm{pH}$ range of 4.0-7.0, higher removal of $\mathrm{GV}$ was observed. The decrease from this point forward may be due to the reason that $\mathrm{GV}^{+}$may be converted into $\mathrm{GV}$ leucocarbinol (nonionized form) [56].

3.3. Adsorption Kinetics of $G V$ Removal and Influence of Contact Time. For understanding the entire process, reaction mechanism implicated in the reactions, like pseudo-first order and pseudo-second order, is being evaluated. The rate equation has been established by Lagergren [57] for pseudofirst order and its linear form can be represented as

$$
\ln \left(q_{e-} q_{t}\right)=\ln q_{e}-k_{1} t .
$$

The rate constant $k_{1}$ (intercept) and equilibrium sorption capacity $q_{e}$ (slope) are enlisted in Table 2 along with the $R^{2}$ being calculated from a linear plot between $\ln$ $\left(q_{e}-q_{t}\right)$ and $t$. It is showed from the current study that the analysis data have not been abiding by the pseudo-firstorder kinetics.

Ho and McKay's pseudo-second-order model [58] signifies the adsorption capacity and is represented in linear form as

$$
\frac{t}{q_{t}}=\frac{1}{h}+\frac{t}{q_{e}} .
$$

The initial sorption rate, $h(\mathrm{mg} / \mathrm{g} / \mathrm{min})$, is determined by applying the following equation:

$$
h=k_{2} q_{e}^{2}
$$

The rate constant $k_{2}$ (intercept) and $q_{e}$ (slope) are enlisted in Table 2. Furthermore, the $R^{2}$ for the second order is displayed admirably as a comparison to the firstorder $R^{2}$. It is implied from Table 2 that the pseudosecond-order kinetic model is favorable in the adsorption mechanism. The $q_{e}$ and $q_{c}$ were comparatively closer, also indicating the sorption process abides by the pseudosecond-order kinetic model. 


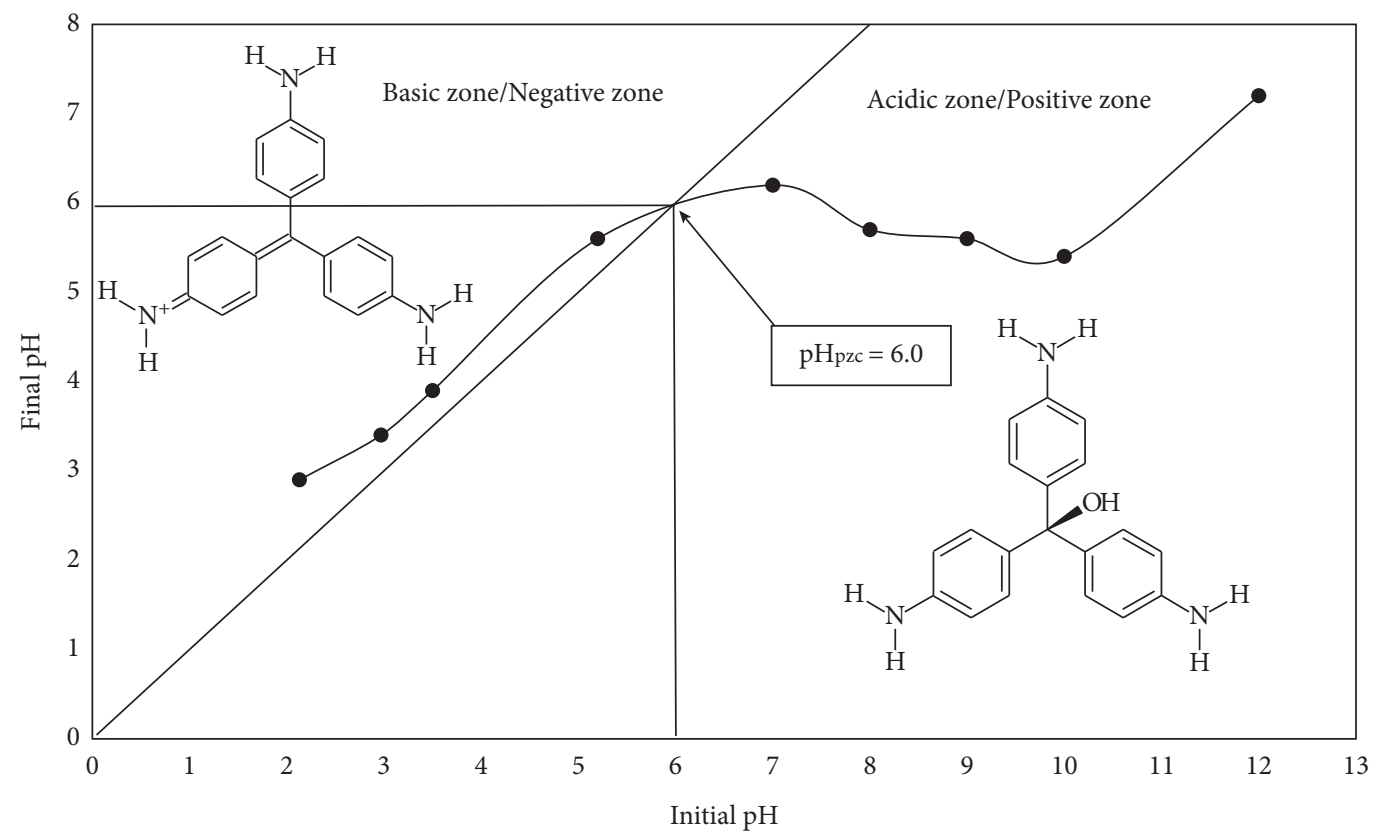

FIgURE 2: $\mathrm{pH}_{\mathrm{pzc}}$ graph for $\mathrm{HAB}$ (by $\mathrm{pH}$ drift method).

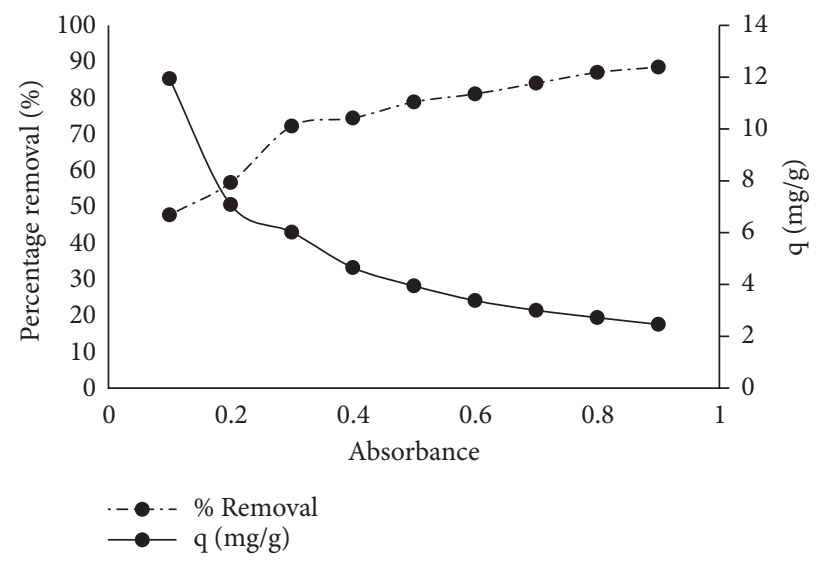

Figure 3: Influence of HAB dosage on GV removal.

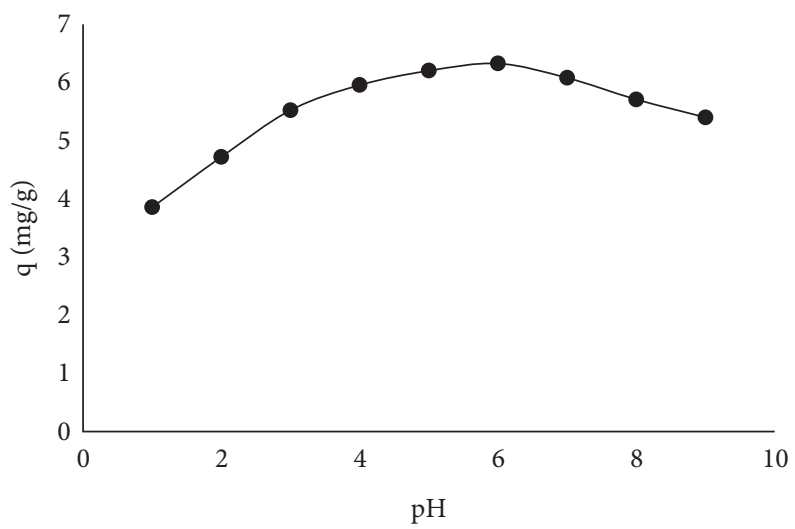

Figure 4: Influence of $\mathrm{pH}$ potency on GV removal. 


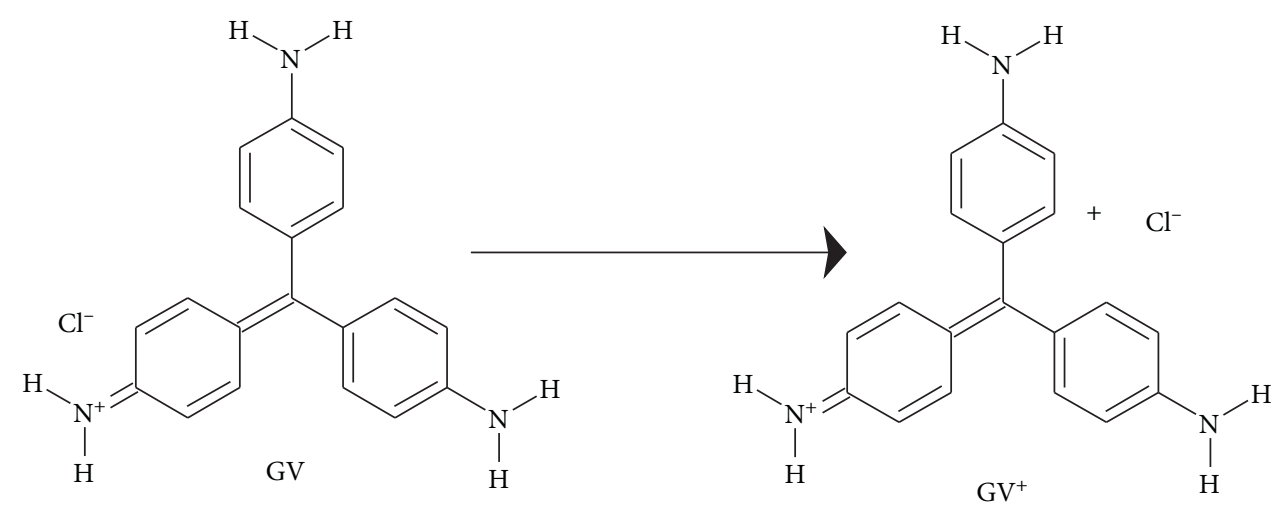

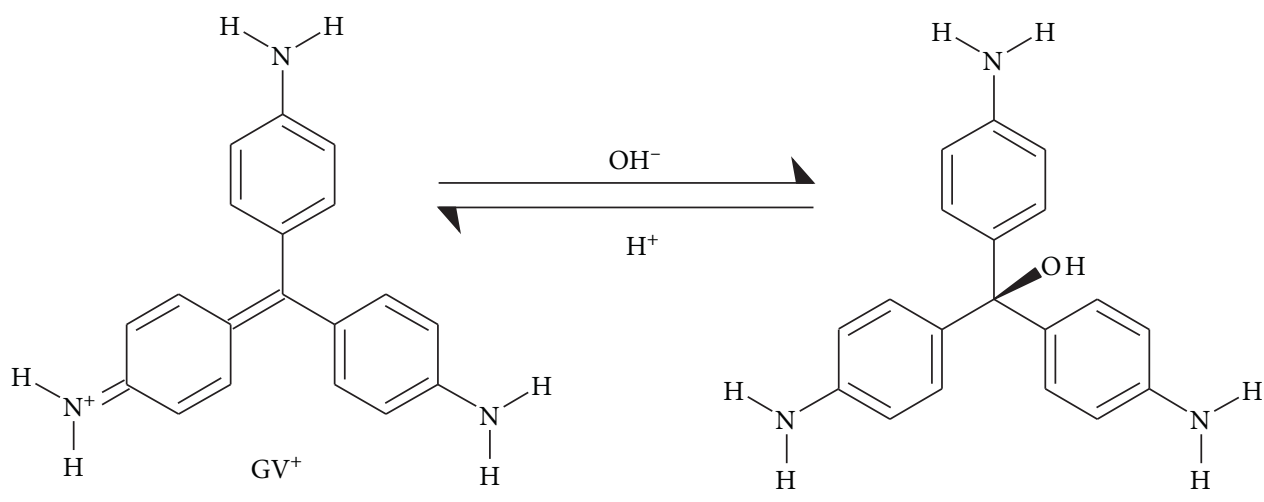

GV Leucocarbinol

Figure 5: Conversion of GV in acidic and basic medium.

TABLE 2: Adsorption kinetics parameters for adsorption of GV onto HAB.

\begin{tabular}{lccccccccc}
\hline $\begin{array}{l}\text { Pseudo-first order } \\
k_{1}\left(\mathrm{~min}^{-1}\right)\end{array}$ & $q_{e(\mathrm{cal})}(\mathrm{mg} / \mathrm{g})$ & $q_{e}(\exp )(\mathrm{mg} / \mathrm{g})$ & $R^{2}$ & $D \%$ & $k_{2}\left(\mathrm{~min}^{-1}\right)$ & $q_{e(\mathrm{cal})}(\mathrm{mg} / \mathrm{g})$ & $q_{e(\exp )}(\mathrm{mg} / \mathrm{g})$ & $R^{2}$ & $D^{2}$ \\
\hline 0.0882 & 3.0627 & 6.931 & 0.9117 & 52.048 & 88.7052 & 6.931 & 6.387 & 0.9981 & 8.5011 \\
\hline
\end{tabular}
follows:

Adsorption capacity difference $(D \%)$ was calculated as

$$
D \%=\frac{q_{c}-q_{e}}{q_{e}} \times 100
$$

The lesser $R^{2}$, as well as greater $D \%$ value calculated for the sorption of GV, demonstrated that the pseudo-first-order kinetics turned out to be not being followed. The observation was made from Figure 6 as well as the factors from Table 2 in which the $R^{2}$ value is near to unity along with lesser $\mathrm{D} \%$ indicating that the pseudo-second-order model is being followed.

The impact of contact time is incredibly important to get the relevant information about the ideal time that is required for the removal of GV. It has been stated according to that that the adsorptive process is carried out in dual phases [59]. During the initial phase, there exists a sudden rise in the amount adsorbed because of available binding sites on the surface of the biosorbent. Into the second phase amount declines since the uninhabited sites onto the surface have been accumulated by dye molecules and therefore come to be inaccessible. The optimal time was found to be 20 to 25 minutes. The maximum period of equilibrium was attained at 25 minutes along with a maximum adsorption capacity of $6.02 \mathrm{mg} / \mathrm{g}$.

3.4. Adsorption Isotherms for GV Removal. The impact of the preliminary dye strength upon the sorption of GV was evaluated within the range of $10-90 \mathrm{mg} / \mathrm{L}$. On minimal concentration, all dye molecules that are present in the solution link up with binding sites within easy reach. However, biosorbent has a limited number of sites that are available for binding which turn up to be inundated along with the increase in concentration. Therefore, consequently at the higher concentrations dye molecules have been left over into a solution which leads to the reduction of removal percentage. On the other hand, the highest possible adsorption capacity for GV increased from 1.39 to $9.54 \mathrm{mg} / \mathrm{g}$ and this information was used in the description of adsorption equilibrium models.

Adsorption isotherms explain how different sorts of adsorbates engage with the adsorbents and that is the reason they are extremely significant for the mechanism of adsorption to 


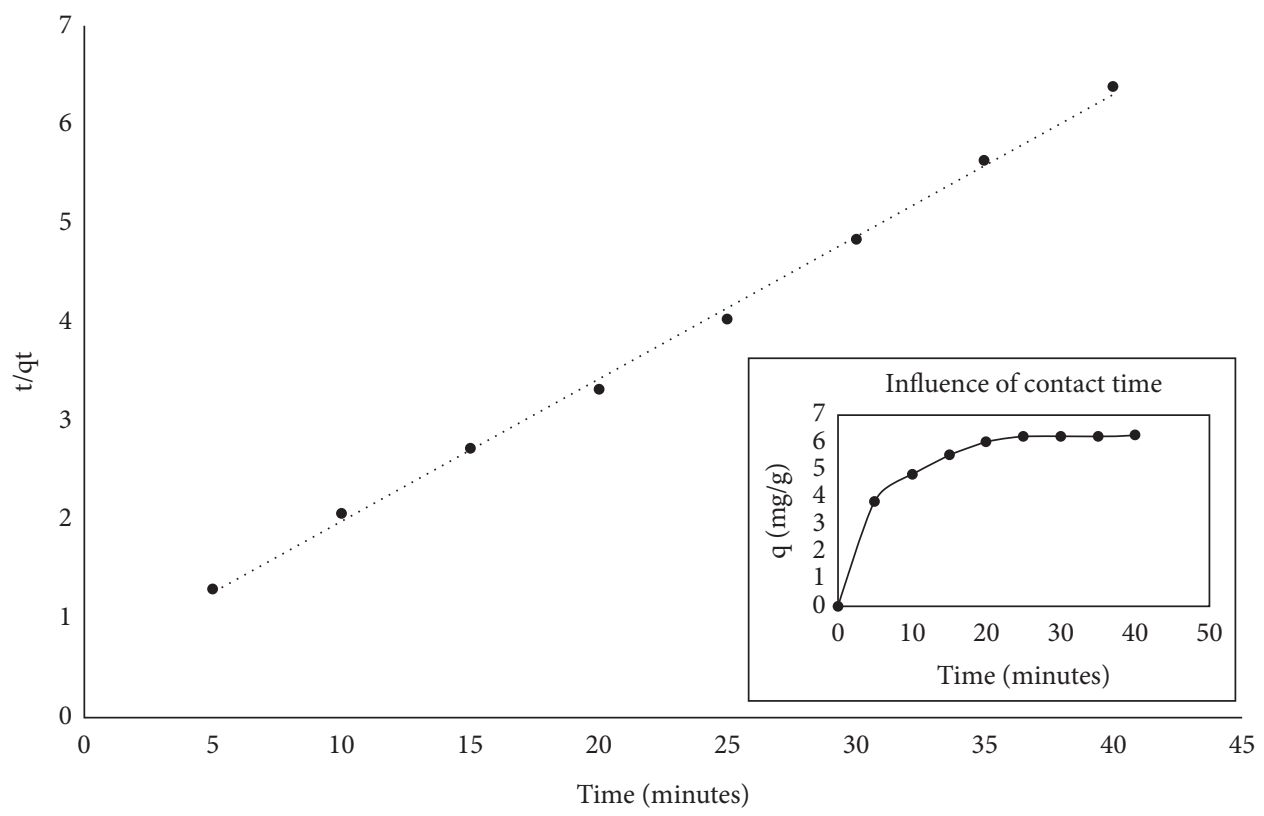

FIGURE 6: Influence of contact time on GV removal.

achieve equilibrium and its impact on the surface characteristics of adsorption. Hence, adsorption isotherms are required for the planning of batch mode adsorption [60, 61]. Such models provide us with the notion regarding the relationships between the adsorbent and adsorbate present in the solution at a constant temperature [62]. For an inquiry of adsorption isotherm, two-parameter isotherms have been examined, i.e., Langmuir and Freundlich isotherms.

The Langmuir model is predicated on the assumption that monolayer adsorption takes place on the homogenous overlay onto a finite number of interaction sites without any interactions [63]. The linear form of the Langmuir model is expressed as follows:

$$
\frac{1}{q_{e}}=\frac{1}{\mathrm{bq}_{\max }} \cdot \frac{1}{C_{e}}+\frac{1}{q_{\max }} .
$$

Its nonlinear form is expressed as follows:

$$
q_{e}=\frac{b \cdot q_{m} C_{e}}{1+b \cdot C_{e}} .
$$

Intended for the positive or unfavorable explanation of the adsorptive process, the separation component constant $R_{L}$ that has no dimension is calculated using the following equation:

$$
R_{L}=\frac{1}{1+\mathrm{bC}_{i}}
$$

This value shows the favorability of isotherm, i.e., $0^{<} R_{L}<1$, unfavorable $\left(R_{L}>1\right)$, linear $\left(R_{L}=1\right)$, or irreversible $\left(R_{L}=0\right)$ [64].

It could be viewed from the correlation coefficient, i.e., 0.9938 , that the experimental information was properly described under the Langmuir model in comparison with the Freundlich model. This suggests the monolayer exposure of the dye onto HAB. The values of $R_{L}$ indicate that the Langmuir model is currently being followed, suggesting that adsorption of GV on the $\mathrm{HAB}$ was favorable. Taking this into account, Langmuir boundaries are given in Table 3 determined from Figure 7.

The Freundlich isotherm illustrates the mixed system of adsorption. This is based on the multilayered adsorption together with a heterogeneous distribution of adsorbates expressed in the following equation [65]:

$$
\log q_{e=} \log K_{f}+\frac{1}{n} \log C_{e} \text {. }
$$

Its nonlinear form is expressed as follows:

$$
q_{e}=K_{f} \cdot C_{e}^{1 / n} .
$$

The Freundlich constant " $n$ " reveals the power of adsorption; if " $1 / n$ " is less than unity, it is going to illustrate the favorable adsorption and if " $1 / n$ " is more than unity, then it is going to be an unfavorable system. As soon as ' $n$ ' increases, a bond gets stronger. Moreover, " $1 / n$ " represents a heterogeneity factor and " $n$ " demonstrates the measuring of divergence from linearity. If " $n$ " is more than unity, then adsorption exists as physisorption, and then if " $n$ " is less than unity then adsorption is favored by chemisorption as shown in Figure 8 [66]. Linear adsorption occurs when " $n$ " is equivalent to or near to unity.

It can be viewed from the $R^{2}$ value that the biosorption of $\mathrm{GV}$ on HAB failed to abide by the Freundlich model as seen from Table 3. The value of " $n$ " was found to be greater than unity, i.e., 1.67, signifying the physisorption.

The described models were to make a comparison by applying the root mean square error (RMSE) values calculated as follows:

$$
\mathrm{RMSE}=\sqrt{\frac{\sum\left(q_{e(\mathrm{cal})}-q_{e(\mathrm{exp})}\right)^{2}}{N}} .
$$


TABLE 3: Adsorption isotherms parameters for adsorption of GV onto HAB.

\begin{tabular}{lccccccccc}
\hline $\begin{array}{l}\text { Langmuir } \\
q_{\max }(\mathrm{mg} / \mathrm{g})\end{array}$ & $b(\mathrm{mg} / \mathrm{L})$ & $R_{L}$ & $R^{2}$ & RMSE & $K_{F}$ & $n$ & $1 / n$ & $R^{2}$ & RMSE \\
\hline 13.21 & 0.07 & $0.59-0.14$ & 0.9938 & 0.13044 & 1.23 & 1.67 & 0.60 & 0.9564 & 0.195 \\
\hline
\end{tabular}

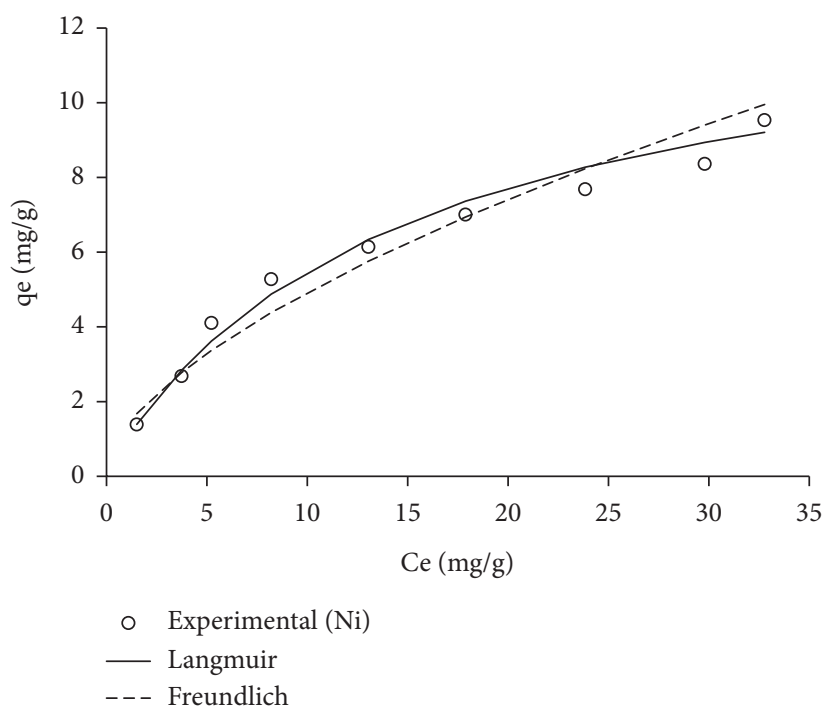

FIgURE 7: Nonlinear isotherm plots for Langmuir and Freundlich models.

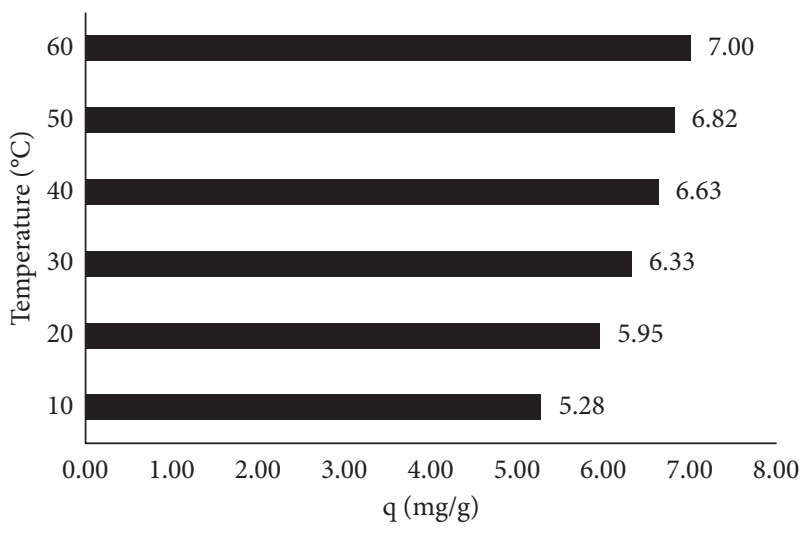

FIGURE 8: Influence of temperature on GV removal.

The RMSE value computed from the nonlinear plot was discovered to be the smallest in the case of the Langmuir model demonstrating its fitness to our experimental data.

\subsection{Influence of Temperature on GV Removal and Thermo-} dynamics Study. Consider the adsorption thermodynamic study conducted in the perspective of the practical implementation is essential as it provides key information regarding the viability, spontaneity, and thermal nature of the adsorption response. To examine the temperature impact on the removal process, the adsorption experiments have been carried out within a temperature range of 283.16 to $333.16 \mathrm{~K}$.

The factors from this research are intended for determining enthalpy $\left(\Delta \mathrm{H}^{\circ}\right)$, entropy $\left(\Delta \mathrm{S}^{\circ}\right)$, and free energy $\left(\Delta \mathrm{G}^{\circ}\right)$. The adsorption capacity of $\mathrm{HAB}$ for $\mathrm{GV}$ rises with an increase in temperature as shown in Figure 8. This tendency is perhaps a result of the opening of additional active sites by the rise of temperature. Thermodynamics parameters were computed by using the following equations and shown in Table 4 [67]:

$$
\begin{aligned}
\Delta G^{\circ} & =\Delta H^{\circ}-T \Delta S^{\circ}, \\
\Delta G^{\circ} & =-\mathrm{RT} \ln K_{D}, \\
\ln K_{D} & =\frac{\Delta S^{\circ}}{R}-\frac{\Delta H^{\circ}}{R T}, \\
K_{D} & =\frac{C_{o}-C_{e}}{C_{e}} .
\end{aligned}
$$

The values of $\Delta S^{\circ}$ and $\Delta H^{\circ}$ can be determined from intercept and slope from the linear plot of $\Delta G^{\circ}$ versus $T(K)$. The corresponding values of free energy have been calculated by utilizing the value of $\mathrm{K}$ at various temperatures. The results are shown in Table 4. The negative values of $\Delta G^{\circ}$ confirm the feasible and spontaneous nature of the sorption of GV onto HAB. When the temperature of the entire system rose, the negativity of $\Delta G^{\circ}$ likewise increased and demonstrated that the high temperature has a synergistic impact on the favorability of the method. The positive value of $\Delta H^{\circ}$ indicates that the adsorption reaction is endothermic.

A certain deduction amount of enthalpy is being used for the classification of adsorption as per physisorption as well as chemisorption. If bonding strengths were not more than $84 \mathrm{~kJ} / \mathrm{mol}$, it is regarded as physisorption and then if within the range of 84 to $420 \mathrm{~kJ} / \mathrm{mol}$ it is explained as 
TABLE 4: Thermodynamics parameters for removal of GV.

\begin{tabular}{cccc}
\hline Dye & Temperature $(K)$ & $\Delta G^{\circ}(\mathrm{kJ} / \mathrm{mol})$ & $\Delta H^{\circ}$ \\
\hline & 283.16 & -1.28442 & $\Delta S^{\circ}$ \\
& 293.16 & -2.23697 & 16.858 \\
GV & 303.16 & -2.89200 & 0.0648 \\
& 313.16 & -3.54595 & \\
& 323.16 & -4.04315 & -4.60381 \\
\hline
\end{tabular}

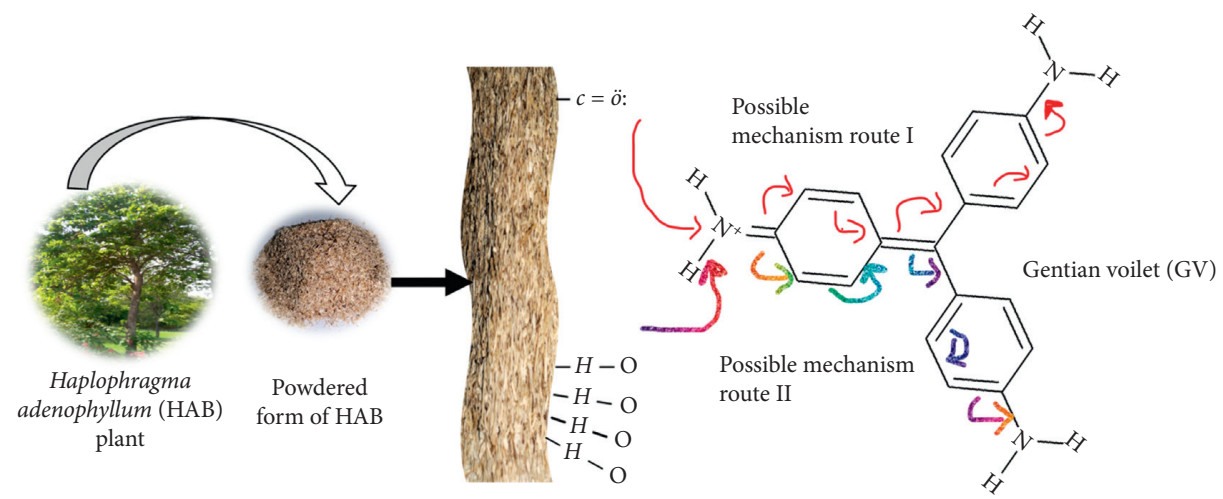

FIgUre 9: Possible mechanism routes of GV removal by HAB.

TABLE 5: Comparison of GV sorption onto various used adsorbents.

\begin{tabular}{|c|c|c|}
\hline Biomass & $q_{\max }(\mathrm{mg} / \mathrm{g})$ & Reference \\
\hline Moringa oleifera pod husk & 156.250 & [69] \\
\hline Modified fly ash & 38.57 & [39] \\
\hline Lemongrass leaf combined with cellulose acetate & 36.10 & {$[44]$} \\
\hline Roots of Eichhornia crassipes & 20.84 & {$[70]$} \\
\hline Grapefruit peel & 24.31 & {$[11]$} \\
\hline Ginger waste & 18.58 & [7] \\
\hline Modified rice husk & 35.12 & {$[51]$} \\
\hline Corn stalks & 9.643 & {$[43]$} \\
\hline Terminalia arjuna sawdust waste & 45.99 & [71] \\
\hline Almond shell AC & 625.0 & {$[72]$} \\
\hline Typha latifolia activated carbon (TLAC) & 2.375 & {$[73]$} \\
\hline Water hyacinth & 322.58 & {$[40]$} \\
\hline Haplophragma adenophyllum & 13.21 & This study \\
\hline
\end{tabular}

chemisorption. Therefore, the value of enthalpy, i.e., $16.858 \mathrm{~kJ} / \mathrm{mol}$, indicated the physisorption adsorption. The positive value of $\Delta S^{\circ}$, i.e., 0.0648 , has demonstrated that adsorption happens due to the energy rearrangement among a small number of molecules which expanded per the rise in the adsorption that provides a positive value of entropy, and consequently solid-surface interaction unpredictability increases [68].

3.6. Proposed Mechanism of GV Removal by HAB. FTIR studies revealed that two potential binding sites play their role in binding the $\mathrm{GV}$ with the structure of $\mathrm{HAB}$, the carbonyl groups and the hydroxyl groups. The possible attachment mechanism of GV structure with these groups is illustrated in Figure 9.
3.7. Regeneration Study. They were done in three consecutive cycles and it was found that third time reused HAB can adsorb $77 \%$ of $\mathrm{GV}$ dye. Future research is in progress to use biowaste for metal sequestration, activated carbon preparation, microwave assisted chemical modification, and removal of other dyes.

3.8. Comparison with Other Biosorbents for GV Removal. This study was also compared with other biosorbents capacities for GV removal. The comparison is tabulated in Table 5. The raw novel Haplophragma adenophyllum in this study causes a noteworthy variation in the biosorption capacity for the removal of GV. Hence, we can say that this biomass can be used as a potential adsorbent for the GV removal from the medium. 


\section{Conclusion}

In the current study, Haplophragma adenophyllum was utilized as efficient biowaste for the cost-effective removal of GV dye from simulated wastewater in a batch mode. From the above experimental data, the removal of GV decreased as we increased the dye concentration with the limited amount of HAB in a solution. The higher removal was observed at $\mathrm{pH} 6.0$ potency. The $q_{\max }$ was found out to be $13.21 \mathrm{mg} / \mathrm{g}$. The equilibrium data fitted well in the Langmuir isotherm indicating the monolayer adsorption onto the HAB surface. The kinetic analysis indicating the physisorption phenomenon fitted well in the pseudo-second-order model. The obtained thermodynamics data, i.e., Gibbs free energy $\left(\Delta G^{\circ}\right)$ and enthalpy $\left(\Delta H^{\circ}\right)$, along with entropy $\left(\Delta S^{\circ}\right)$, depict the spontaneous and endothermic nature of the mechanism. All the obtained data revealed that $\mathrm{HAB}$ can be utilized as a cheap and encouraging adsorbent for the removal of GV dye from simulated wastewater as well as from industrial wastewater with some modifications.

\section{Data Availability}

All the data related to this work are presented in Results section along with references.

\section{Conflicts of Interest}

The authors have no conflicts of interest regarding publication of this paper.

\section{Acknowledgments}

The authors are thankful to University of the Punjab, Pakistan, for analysis services.

\section{References}

[1] M. R. Awual, "An efficient composite material for selective lead (ii)(II) monitoring and removal from wastewater," Journal of Environmental Chemical Engineering, vol. 7, Article ID 103087, 2019.

[2] E. Alver and A. Ü. metin, "Anionic dye removal from aqueous solutions using modified zeolite: adsorption kinetics and isotherm studies," Chemical Engineering Journal, vol. 200-202, pp. 59-67, 2012.

[3] S. Buthelezi, A. Olaniran, and B. pillay, "Textile dye removal from wastewater effluents using bioflocculants produced by indigenous bacterial isolates," Molecules, vol. 17, no. 12, pp. 14260-14274, 2012.

[4] G. Crini, "Non-conventional low-cost adsorbents for dye removal: a review," Bioresource Technology, vol. 97, no. 9, pp. 1061-1085, 2006.

[5] M. Vakili, M. Rafatullah, B. Salamatinia et al., "Application of chitosan and its derivatives as adsorbents for dye removal from water and wastewater: a review," Carbohydrate Polymers, vol. 113, pp. 115-130, 2014.

[6] A. C. D. Filho, A. C. Mazzocato, G. L. Dotto, P. S. Thue, and F. A. Pavan, "Eragrostis plana nees as a novel eco-friendly adsorbent for removal of crystal violet from aqueous solutions," Environmental Science and Pollution Research, vol. 24, no. 24, pp. 19909-19919, 2017.
[7] R. Kumar and R. Ahmad, "Biosorption of hazardous crystal violet dye from aqueous solution onto treated ginger waste (tgw)," Desalination, vol. 265, no. 1-3, pp. 112-118, 2011.

[8] K. Kanagamani, P. Muthukrishnan, K. Saravanakumar, K. Shankar, and A. Kathiresan, "Photocatalytic degradation of environmental perilous gentian violet dye using leucaenamediated zinc oxide nanoparticle and its anticancer activity," Rare Metals, vol. 38, no. 4, pp. 277-286, 2019.

[9] R. Ahmad, "Studies on adsorption of crystal violet dye from aqueous solution onto coniferous pinus bark powder (cpbp)," Journal of Hazardous Materials, vol. 171, no. 1-3, pp. 767-773, 2009.

[10] A. Mittal, J. Mittal, A. Malviya, D. Kaur, and V. K. Gupta, "Adsorption of hazardous dye crystal violet from wastewater by waste materials," Journal of Colloid and Interface Science, vol. 343, no. 2, pp. 463-473, 2010.

[11] A. Saeed, M. Sharif, and M. Iqbal, "Application potential of grapefruit peel as dye sorbent: kinetics, equilibrium and mechanism of crystal violet adsorption," Journal of Hazardous Materials, vol. 179, no. 1-3, pp. 564-572, 2010.

[12] J. Qin, F. Qiu, X. Rong, J. Yan, H. Zhao, and D. Yang, "Adsorption behavior of crystal violet from aqueous solutions with chitosan-graphite oxide modified polyurethane as an adsorbent," Journal of Applied Polymer Science, vol. 132, 2015.

[13] Y. J. Chan, M. F. Chong, C. L. Law, and D. G. hassell, "A review on anaerobic-aerobic treatment of industrial and municipal wastewater," Chemical Engineering Journal, vol. 155, no. 1-2, pp. 1-18, 2009.

[14] M. C. Diez, "Biological aspects involved in the degradation of organic pollutants," Journal of Soil Science and Plant Nutrition, vol. 10, pp. 244-267, 2010.

[15] S. A. Butani and S. J. J. I. J. S. T. M. Mane, "Coagulation/ flocculation process for cationic anionic dye removal using water treatment residuals-a review," International Journal of Science Technology and Engineering, vol. 6, pp. 121-125, 2017.

[16] E. Guibal and J. Roussy, "Coagulation and flocculation of dyecontaining solutions using a biopolymer (chitosan)," Reactive and Functional Polymers, vol. 67, no. 1, pp. 33-42, 2007.

[17] A. Azimi, A. Azari, M. Rezakazemi, and M. Ansarpour, "Removal of heavy metals from industrial wastewaters: a review," ChemBioEng Reviews, vol. 4, no. 1, pp. 37-59, 2017.

[18] P. V. Nidheesh, M. Zhou, and M. A. Oturan, "An overview on the removal of synthetic dyes from water by electrochemical advanced oxidation processes," Chemosphere, vol. 197, pp. 210-227, 2018.

[19] M. M. Hassan and C. M. Carr, "A critical review on recent advancements of the removal of reactive dyes from dyehouse effluent by ion-exchange adsorbents," Chemosphere, vol. 209, pp. 201-219, 2018.

[20] I. Levchuk, J. J. Rueda Márquez, and M. Sillanpää, "Removal of natural organic matter (NOM) from water by ion exchange - a review," Chemosphere, vol. 192, pp. 90-104, 2018.

[21] S. Chakraborty, M. K. Purkait, S. Dasgupta, S. De, J. K. Basu, and P. Technology, "Nanofiltration of textile plant effluent for color removal and reduction in cod," Separation and Purification Technology, vol. 31, no. 2, pp. 141-151, 2003.

[22] M. Peydayesh, T. Mohammadi, and O. Bakhtiari, "Effective treatment of dye wastewater via positively charged tetamwcnt/pes hybrid nanofiltration membranes," Separation and Purification Technology, vol. 194, pp. 488-502, 2018.

[23] K. Xu, G.-M. zeng, J.-h. Huang et al., "Removal of cd2+ from synthetic wastewater using micellar-enhanced ultrafiltration with hollow fiber membrane," Colloids and Surfaces A: Physicochemical and Engineering Aspects, vol. 294, no. 1-3, pp. 140-146, 2007. 
[24] A. Y. Zahrim and N. Hilal, "Treatment of highly concentrated dye solution by coagulation/flocculation-sand filtration and nanofiltration," Water Resources and Industry, vol. 3, pp. 23-34, 2013.

[25] V. Khandegar and A. K. Saroha, "Electrocoagulation for the treatment of textile industry effluent-a review," Journal of Environmental Management, vol. 128, pp. 949-963, 2013.

[26] T. Ölmez, "The optimization of $\mathrm{Cr}$ (VI) reduction and removal by electrocoagulation using response surface methodology," Journal of Hazardous Materials, vol. 162, no. 2-3, pp. 1371-1378, 2009.

[27] S. Al-Amshawee, M. Y. B. M. Yunus, A. A. M. Azoddein, D. G. Hassell, I. H. Dakhil, and J. Hasan, "Electrodialysis desalination for water and wastewater: a review," Chemical Engineering Journal, vol. 380, Article ID 122231, 2020.

[28] E. Korngold, K. Kock, and H. Strathmann, "Electrodialysis in advanced waste water treatment," Desalination, vol. 24, no. 1-3, pp. 129-139, 1977.

[29] A. Khelifa, S. Moulay, and A. W. Naceur, "Treatment of metal finishing effluents by the electroflotation technique," Desalination, vol. 181, no. 1-3, pp. 27-33, 2005.

[30] V. A. Kolesnikov, V. I. 'Il'in, and A. V. Kolesnikov, "Electroflotation in wastewater treatment from oil products, dyes, surfactants, Ligands, and biological pollutants: a review," Theoretical Foundations of Chemical Engineering, vol. 53, no. 2, pp. 251-273, 2019.

[31] S. N. Malik, P. C. Ghosh, A. N. Vaidya, and S. N. Mudliar, "Hybrid ozonation process for industrial wastewater treatment: principles and applications: a review," Journal of Water Process Engineering, vol. 35, Article ID 101193, 2020.

[32] J. Wang and H. J. Chen, "Catalytic ozonation for water and wastewater treatment: recent advances and perspective," Science of the Total Environment, vol. 704, Article ID 135249, 2020.

[33] Y. Yang, I. Wyatt, D. Travis, and M. Bahorsky, "Decolorization of dyes using uv/h 2 o 2 photochemical oxidation," vol. 30, 1998.

[34] L. F. Greenlee, D. F. lawler, B. D. freeman, B. Marrot, and P. Moulin, "Reverse osmosis desalination: water sources, technology, and today's challenges," 'Water Research, vol. 43, no. 9, pp. 2317-2348, 2009.

[35] M. Qasim, M. Badrelzaman, N. N. Darwish, N. A. Darwish, and N. Hilal, "Reverse osmosis desalination: a state-of-the-art review," Desalination, vol. 459, pp. 59-104, 2019.

[36] M. R. Awual, M. M. Hasan, A. Islam, A. M. Asiri, and M. M. J. J. O. M. L. Rahman, "Optimization of an innovative composited material for effective monitoring and removal of cobalt (II) from wastewater," Journal of Molecular Liquids, vol. 298, Article ID 112035, 2020.

[37] M. Awual, "A facile composite material for enhanced cadmium (ii) ion capturing from wastewater," Journal of Environmental Chemical Engineering, vol. 7, Article ID 103378, 2019.

[38] M. R. Awual, "Novel conjugated hybrid material for efficient lead(II) capturing from contaminated wastewater," Materials Science and Engineering: C, vol. 101, pp. 686-695, 2019.

[39] S. Chakraborty, A. Mukherjee, S. Das, N. R. Maddela, S. Iram, and P. Das, "Study on isotherm kinetics and thermodynamics of adsorption of crystal violet dye by calcium oxide modified fly ash," Environmental Engineering Research, vol. 26, 2021.

[40] M. R. Kulkarni, T. Revanth, A. Acharya, and P. Bhat, "Removal of crystal violet dye from aqueous solution using water hyacinth: equilibrium, kinetics and thermodynamics study," Resource-Efficient Technologies, vol. 3, no. 1, pp. 71-77, 2017.
[41] 1. R. Martins, J. A. V. Rodrigues, O. F. H. Adarme et al., "Optimization of cellulose and sugarcane bagasse oxidation: application for adsorptive removal of crystal violet and auramine-o from aqueous solution," Journal of Colloid and Interface Science, vol. 494, pp. 223-241, 2017.

[42] M. Massoudinejad, H. Rasoulzadeh, and M. Ghaderpoori, "Magnetic chitosan nanocomposite: fabrication, properties, and optimization for adsorptive removal of crystal violet from aqueous solutions," Carbohydrate Polymers, vol. 206, pp. 844-853, 2019.

[43] U. L. Muhammad, Z. U. Zango, H. A. Kadir, and A. Usman, "Crystal violet removal from aqueous solution using corn stalk biosorbent," Science World Journal, vol. 14, pp. 133-138, 2019.

[44] K. N. A. Putri, A. Keereerak, and W. Chinpa, "Novel cellulosebased biosorbent from lemongrass leaf combined with cellulose acetate for adsorption of crystal violet," International Journal of Biological Macromolecules, vol. 156, 2020.

[45] M. T. Yagub, T. K. Sen, S. Afroze, and H. M. Ang, "Dye and its removal from aqueous solution by adsorption: a review," Advances in Colloid and Interface Science, vol. 209, pp. 172184, 2014.

[46] M. Nujic, N. Velic, and M. Habuda-Stanić, "Application of date-palm fibres for the wastewater treatment," Sustainable Agriculture Reviews, vol. 34, 2019.

[47] N. Fiol and I. Villaescusa, "Determination of sorbent point zero charge: usefulness in sorption studies," Environmental Chemistry Letters, vol. 7, no. 1, pp. 79-84, 2009.

[48] N. Saha, M. Volpe, L. Fiori, R. Volpe, A. Messineo, and M. T. Reza, "Cationic dye adsorption on hydrochars of winery and citrus juice industries residues: performance, mechanism, and thermodynamics," Energies, vol. 13, no. 18, p. 4686, 2020.

[49] D. H. K. Reddy, K. Seshaiah, A. V. R. reddy, and S. M. Lee, "Optimization of $\mathrm{Cd}(\mathrm{II}), \mathrm{Cu}(\mathrm{II})$ and $\mathrm{Ni}(\mathrm{II})$ biosorption by chemically modified Moringa oleifera leaves powder," Carbohydrate Polymers, vol. 88, no. 3, pp. 1077-1086, 2012.

[50] P. Saha, S. Chowdhury, S. Gupta, and I. Kumar, "Insight into adsorption equilibrium, kinetics and thermodynamics of Malachite Green onto clayey soil of Indian origin," Chemical Engineering Journal, vol. 165, no. 3, pp. 874-882, 2010.

[51] S. Chakraborty, S. Chowdhury, and P. Das Saha, "Adsorption of crystal violet from aqueous solution onto naoh-modified rice husk," Carbohydrate Polymers, vol. 86, no. 4, pp. 1533-1541, 2011.

[52] F. A. Pavan, E. S. Camacho, E. C. Lima, G. L. Dotto, V. T. A. Branco, and S. L. P. Dias, "Formosa papaya seed powder (FPSP): preparation, characterization and application as an alternative adsorbent for the removal of crystal violet from aqueous phase," Journal of Environmental Chemical Engineering, vol. 2, no. 1, pp. 230-238, 2014.

[53] S. Chowdhury, S. Chakraborty, and P. D. Das, "Adsorption of crystal violet from aqueous solution by citric acid modified rice straw: equilibrium, kinetics, and thermodynamics," Separation Science and Technology, vol. 48, no. 9, pp. 13391348, 2013.

[54] L. Mukherjee, N. Mitra, P. K. Bhattacharya, and S. P. Moulik, "Kinetics in microemulsion medium. 4. Alkaline fading of crystal violet in aqueous (h2o/aerosol ot/isooctane and h2o/ aerosol ot/decane) and nonaqueous (ethylene glycol/aerosol ot/isooctane) microemulsions," Langmuir, vol. 11, no. 8, pp. 2866-2871, 1995.

[55] L. Yong, G. Zhanqi, J. Yuefei et al., "Photodegradation of malachite green under simulated and natural irradiation: 
kinetics, products, and pathways," Journal of Hazardous Materials, vol. 285, pp. 127-136, 2015.

[56] L. García-Río, J. R. Leis, J. C. Mejuto, a. Navarro-Vázquez, j. Pérez-Juste, and P. Rodriguez-Dafonte, "Basic hydrolysis of crystal violet in $\beta$-cyclodextrin/surfactant mixed systems," Langmuir, vol. 20, no. 3, pp. 606-613, 2004.

[57] S. Lagergren, "About the theory of so-called adsorption of soluble substances," Sven Vetenskapsakad Handingarl, vol. 24, pp. 1-39, 1898.

[58] Y. S. Ho and G. Mckay, "Pseudo-second order model for sorption processes," Process Biochemistry, vol. 34, no. 5, pp. 451-465, 1999.

[59] S. M. Al-Garni, "Biosorption of lead by gram-ve capsulated and non-capsulated bacteria," Water S. A.vol. 31, pp. 345-350, 2005.

[60] B. C. S. Ferreira, F. S. Teodoro, A. B. Mageste, L. F. Gil, R. P. De Freitas, and L. V. A. Gurgel, "Application of a new carboxylate-functionalized sugarcane bagasse for adsorptive removal of crystal violet from aqueous solution: kinetic, equilibrium and thermodynamic studies," Industrial Crops and Products, vol. 65, pp. 521-534, 2015.

[61] K. Y. Foo and B. H. Hameed, "Insights into the modeling of adsorption isotherm systems," Chemical Engineering Journal, vol. 156, no. 1, pp. 2-10, 2010.

[62] A. Dubey and S. Shiwani, "Adsorption of lead using a new green material obtained from portulaca plant," International Journal of Environmental Science and Technology, vol. 9, no. 1, pp. 15-20, 2012.

[63] I. Langmuir, "The adsorption of gases on plane surfaces of glass, mica and platinum," Journal of the American Chemical Society, vol. 40, no. 9, pp. 1361-1403, 1918.

[64] R. Han, H. Li, Y. Li, J. Zhang, H. Xiao, and J. Shi, "Biosorption of copper and lead ions by waste beer yeast," Journal of Hazardous Materials, vol. 137, no. 3, pp. 1569-1576, 2006.

[65] H. Freundlich, "About adsorption in solutions," Journal of Physical Chemistry A, vol. 57, pp. 385-470, 1907.

[66] A. Murugesan, L. Ravikumar, V. Sathyaselvabala et al., "Removal of $\mathrm{Pb}$ (II), $\mathrm{Cu}$ (II) and $\mathrm{Cd}(\mathrm{II})$ ions from aqueous solution using polyazomethineamides: equilibrium and kinetic approach," Desalination, vol. 271, no. 1-3, pp. 199-208, 2011.

[67] D. H. Everett, "The thermodynamics of adsorption. Part IIthermodynamics of monolayers on solids," Transactions of the Faraday Society, vol. 46, pp. 942-957, 1950.

[68] C.-Y. Kuo, C.-H. Wu, and J.-Y. Wu, "Adsorption of direct dyes from aqueous solutions by carbon nanotubes: determination of equilibrium, kinetics and thermodynamics parameters," Journal of Colloid and Interface Science, vol. 327, no. 2, pp. 308-315, 2008.

[69] A. Keereerak and W. Chinpa, "A potential biosorbent from Moringa oleifera pod husk for crystal violet adsorption: kinetics, isotherms, thermodynamic and desorption studies," ScienceAsia, vol. 46, no. 2, pp. 186-194, 2020.

[70] S. R. Patil, S. S. sutar, and J. P. Jadhav, "Sorption of crystal violet from aqueous solution using live roots of eichhornia crassipes: kinetic isotherm phyto and cyto-genotoxicity studies," Environmental Technology Innovation, vol. 18, Article ID 100648, 2020.

[71] S. Shakoor and A. Nasar, "Adsorptive decontamination of synthetic wastewater containing crystal violet dye by employing Terminalia arjuna sawdust waste," Groundwater for Sustainable Development, vol. 7, pp. 30-38, 2018.

[72] H. A. Ahsaine, M. Zbair, Z. Anfar, Y. Naciri, N. El alem, and M. J. M. T. C. Ezahri, "Cationic dyes adsorption onto high surface area 'almond shell'activated carbon: kinetics,"
Equilibrium Isotherms and Surface Statistical Modeling, vol. 8, pp. 121-132, 2018.

[73] H. J. Kumari, P. Krishnamoorthy, T. Arumugam, S. Radhakrishnan, and D. Vasudevan, "An efficient removal of crystal violet dye from waste water by adsorption onto tlac/ chitosan composite: a novel low cost adsorbent," International Journal of Biological Macromolecules, vol. 96, pp. 324-333, 2017. 